\title{
Research on the Measures to Improve Air Quality at Tiny Areas of Scenic Spots in Chengdu Based on Ecological Design
}

\author{
Jun Bi \\ College of Applied Technology \\ Xihua University \\ Chengdu, Sichuan, 610039
}

\author{
Chun Huang \\ Chengdu Environmental Monitoring Center Station \\ Chengdu, Sichuan, 610000
}

\author{
Lin Wang \\ College of Applied Technology \\ Xihua University \\ Chengdu, Sichuan, 610039
}

\begin{abstract}
In order to keep tourists healthy, it is necessary to improve air quality in scenic spots. Based on status quo of air in Chengdu, this article summarizes sources of air pollution and main pollutants in scenic spots, Chengdu, introducing a harmless sustainable design concept. In the meantime, it raises specific measures for air control, offering innovation design from technique, users and serviceable range. The analytical method and specific measures present new thought for air pollution control in other scenic spots across the country.
\end{abstract}

Keywords-eco-design; urban scenic spots; air quality; ecoproducts; tiny area

\section{INTRODUCTION}

Nowadays, haze has become a frequent phenomenon in our society; it has a wide spread and long duration, causing inconvenience to the public and threatening health of the people, which has been highly taken by the society and authorities. Facing worse weather as haze, a lot of scenic spots have released new slogans such as "fresh air travel" and "say no to haze, clean air travel". Since most scenic spots are located in cities, it has limited abilities to purify air, how to keep fresh air in scenic spots and be harmless lungs in cities has been a tough problem in scenic spot management in cities.

According to CNKI academic big data analysis, eco-design research started in 1987, reaching the peak in 2013, up to now, there are more than 7000 articles concerned. Eco-design, also called green design, life circle design or environmental design, means that environmental factors are included to design in order to help determine the design decision making direction and guide to produce a more sustainable production and

Fund Program: Sichuan Province Cyclic Economy Research Center in 2017 (XHJJ-1712); Supported by the Open Research Subject of Tourism Development Research Center of Sichuan (SCTRC) in 2017 (LYC17-12);

A Project Supported by Sichuan Landscape and Recreation Research Center in 2017 (JGYQ2017034). consumption system. Taking the scenic spot in Chengdu, this article introduces eco-design concept, making redesign and innovation for air pollution control in the spot from technique, user and serviceable range. "Fig. 1"

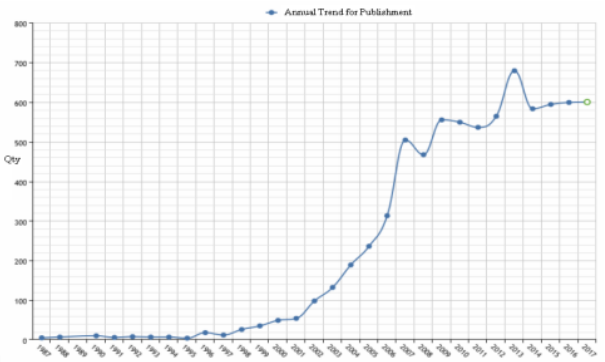

Fig. 1. Eco-design research trend.

\section{NATIONAL STANDARDS AND STATUS QUO OF AIR IN DOWNTOWN AREA, CHENGDU}

\section{A. Ambient Air Quality Standards}

According to GB3095 Ambient Air Quality Standard (Version 2012) "Table I", environmental functional areas are divided into two categories: Category I: natural protection area, scenic spot and other areas needing special protection; Category II: residential district, a mixed area of commerce, traffic and residence, cultural area, industrial area and rural area. The ambient air functional areas requires that category I areas apply to Level I concentration value limit, Category II areas apply Level II concentration value limit. Quality requirements in categories I and II ambient functional areas are given in "Table I". 
TABLE I. GB3095 AmBIENT Air QuALITY STANDARD (VERSION 2012) CONCENTRATION VALUE LIMIT OF BASIC ITEMS IN AIR POLLUTANTS (CATEGORY I AREAS APPLY TO LEVEL I CONCENTRATION VALUE LIMIT, CATEGORY II AREAS APPLY LEVEL II CONCENTRATION VALUE LIMIT)

\begin{tabular}{|c|c|c|c|c|c|}
\hline \multirow[t]{2}{*}{ No } & \multirow[t]{2}{*}{ Pollutant } & \multirow[t]{2}{*}{ Average Time } & \multicolumn{2}{|c|}{$\begin{array}{l}\text { Concentration } \\
\text { Value Limit }\end{array}$} & \multirow[t]{2}{*}{ Unit } \\
\hline & & & Level I & Level II & \\
\hline \multirow[t]{3}{*}{1} & \multirow{3}{*}{$\begin{array}{l}\text { Sulfur } \\
\left(\mathrm{So}_{2}\right)\end{array}$} & Annual average & 20 & 60 & \multirow[t]{6}{*}{$\mu \mathrm{g} / \mathrm{m} 3$} \\
\hline & & Average within 24 hours & 50 & 150 & \\
\hline & & Average within 1 hour & 150 & 500 & \\
\hline \multirow[t]{3}{*}{2} & \multirow{3}{*}{$\begin{array}{l}\text { Nitrogen } \\
\text { dioxide }\left(\mathrm{No}_{2}\right)\end{array}$} & Annual average & 40 & 40 & \\
\hline & & Average within 24 hours & 80 & 80 & \\
\hline & & Average within 1 hour & 200 & 200 & \\
\hline \multirow[t]{2}{*}{3} & \multirow{2}{*}{$\begin{array}{l}\text { Carbon } \\
\text { oxide }(\mathrm{CO})\end{array}$} & Average within 24 hours & 4 & 4 & \multirow[t]{2}{*}{$\mathrm{mg} / \mathrm{m} 3$} \\
\hline & & Average within 1 hour & 10 & 10 & \\
\hline \multirow[t]{2}{*}{4} & \multirow[t]{2}{*}{ Ozone $\left(\mathrm{O}_{3}\right)$} & $\begin{array}{l}\text { Average within 1day (8h at } \\
\text { most) }\end{array}$ & 100 & 160 & \multirow[t]{6}{*}{$\mu \mathrm{g} / \mathrm{m} 3$} \\
\hline & & Average within 1 hour & 160 & 200 & \\
\hline \multirow[t]{2}{*}{5} & \multirow{2}{*}{$\begin{array}{l}\text { Particle } \text { (size } \\
\text { not more than } \\
10 \mu \mathrm{m})\end{array}$} & Annual average & 40 & 70 & \\
\hline & & Average within 24 hours & 50 & 150 & \\
\hline \multirow[t]{2}{*}{6} & \multirow{2}{*}{$\begin{array}{l}\text { Particle (size } \\
\text { not more than } \\
2.5 \mu \mathrm{m})\end{array}$} & Annual average & 15 & 35 & \\
\hline & & Average within 24 hours & 35 & 75 & \\
\hline
\end{tabular}

\section{B. Status Quo of Air Quality in Chengdu}

High attentions by the public, according to the big dataBaidu search index, "Fig. 2" shows that the air in Chengdu has attracted more and more attentions of the public since 2014, reaching the peak in 2015, still hot in 2016 and 2017.

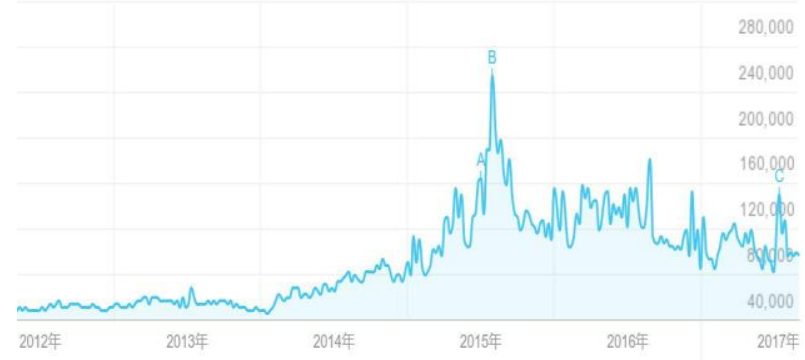

Fig. 2. Baidu search index of air in Chengdu.

The annual environment quality bulletin released by Chengdu environmental monitoring center shows statistic data of annual average concentration of pollutants of main items from 2014 to 2016. According to "Table II", in recent three years, the annual average concentration of $\mathrm{SO}_{2}, \mathrm{CO}, \mathrm{O}_{3}$ are within Level I concentration value limits, reaching category I value limit under national standard; the annual average concentration of $\mathrm{No}_{2}$ is about 0.3 time that national standard concentration limit; the annual average concentration of PM10 is 0.5 time the national standard category II concentration; the annual average concentration of $\mathrm{PM}_{2.5}$ is about 0.8 time the national standard category II concentration. We draw a conclusion that main pollutants for air pollution in Chengdu are $\mathrm{NO}_{2}, \mathrm{PM}_{10}$ (inhalable particles), $\mathrm{PM}_{2.5}$ (fine particles)

\section{Air Conditions in Chengdu}

TABle II. Annula Average Concentration of Main Pollutants FROM 2014 TO 2016, CHENGDU

\begin{tabular}{ccccccc}
\hline Year & SO2 & NO2 & CO & $\mathbf{O}_{3}$ & $\mathbf{P M}_{\mathbf{1 0}}$ & $\mathbf{P M}_{\mathbf{2 . 5}}$ \\
\hline 2014 & 19 & 59 & 2 & 148 & 123 & 77 \\
2015 & 14 & 53 & 2 & 183 & 108 & 64 \\
2016 & 14 & 54 & 1.8 & 168 & 105 & 63 \\
\hline & & & & \multicolumn{5}{c}{ a. Unit: CO: $\mathrm{mg} / \mathrm{m} 3$, others: $\mathrm{mcg} / \mathrm{m} 3}$.
\end{tabular}

"Fig 1" shows, $\mathrm{PM}_{2.5}$ (fine particles) in whole Chengdu exceeds standards, $\mathrm{NO}_{2}$ and $\mathrm{PM}_{10}$ (inhalable particles) are serious in circle I and circle II in Chengdu (Circle I includes Qingyang District, Jinjinag District, Jinniu District, Wuhou District, Chenghua District, New \& Hi-tech Zone; Circle II includes Xindu District, Pixian County, Wendu District, Shuangliu County and Longquanyi District).

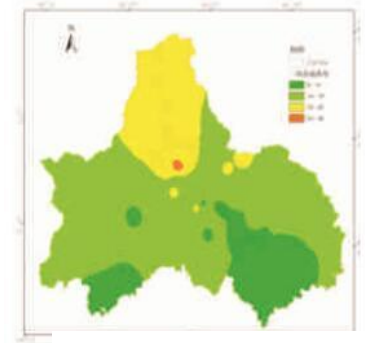

(a) $\mathrm{SO}_{2}$

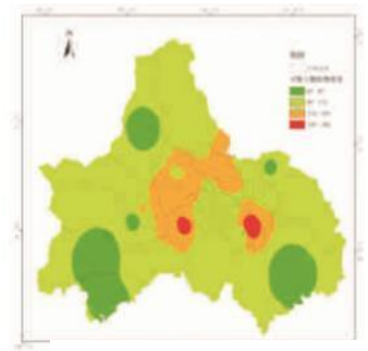

(c) inhalable particles

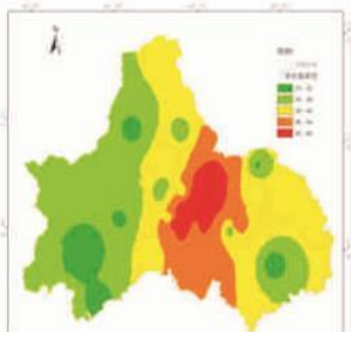

(b) $\mathrm{NO}_{2}$

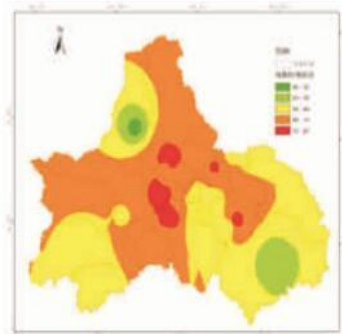

(b) fine particles
Fig. 3. Air pollutant concentration distribution in 2016, Chengdu.

TABLE III. MAIN SCEnIC Spots AT CIRCLE I, ChENGDU

\begin{tabular}{lcccccc}
\hline $\begin{array}{c}\text { Scenic } \\
\text { Spot }\end{array}$ & $\begin{array}{c}\text { Place of } \\
\text { Interest }\end{array}$ & $\begin{array}{c}\text { Beauty } \\
\text { Spot }\end{array}$ & Park & $\begin{array}{c}\text { Botanic } \\
\text { Garden }\end{array}$ & $\begin{array}{c}\text { Amusement } \\
\text { Park }\end{array}$ \\
\hline Qty & 5 & 7 & 6 & 4 & 5 & \\
\hline & & & & & b. Unit: Pc.
\end{tabular}

Main scenic spots in Chengdu are located in Circle I, and the air quality problems are found severe as shown above, so it is extremely urgent to speed up the air pollution abatement. 


\section{1) About $\mathrm{NO}_{2}$, a main pollutant} $\mathrm{Mg} / \mathrm{m} 3$

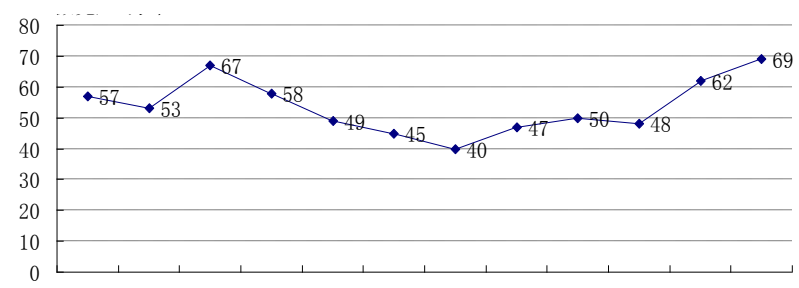

Jan Feb Mar Apr May Jun Jul Aug Sep Oct Nov Dec

Fig. 4. $\mathrm{NO}_{2}$ concentration changes during Jan-Dec, 2016, Chengdu.

In $2016, \mathrm{NO}_{2}$ concentration was $54 \mathrm{mcg} / \mathrm{m} 3$, ranking the 8th within 74 large and medium cities throughout the country. At present, there are basically no air pollution related industrial enterprises in downtown areas, Chengdu, surveys and data analysis show that $\mathrm{NO}_{2}$ concentration is directly related to the tai gas of motor vehicles in the city. The $\mathrm{NO}_{2}$ concentration daily change value has double peaks, which are highly consistent with the rush hours. "Fig. 4"

Surveys of non-air pollution industrial enterprises nearby the scenic spot, the annual average $\mathrm{NO}_{2}$ concentration is $32 \mathrm{mcg} / \mathrm{m} 3$. According to $\mathrm{NO}_{2}$ concentration changes data before and after National Day in "Fig. 2" and the number of tourists in 2016 National Day, the $\mathrm{NO}_{2}$ concentration changes in scenic spots have positive correlation with motor vehicles, and the entry of tourists' vehicles directly caused the increase of $\mathrm{NO}_{2}$ concentration.

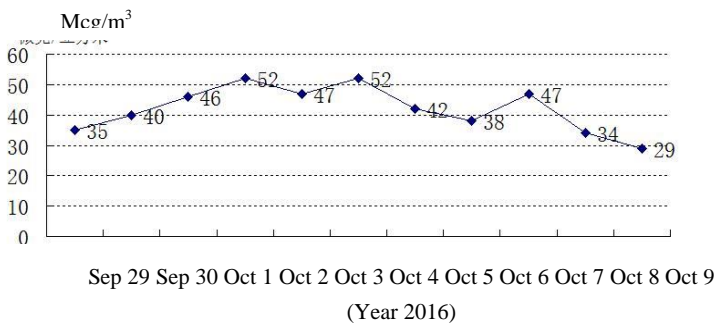

Fig. 5. $\mathrm{NO}_{2}$ concentration changes before and after National Day in a scenic spot, Chengdu, 2016.

\section{2) Main pollutants $P M_{10}, P M_{2.5}$}

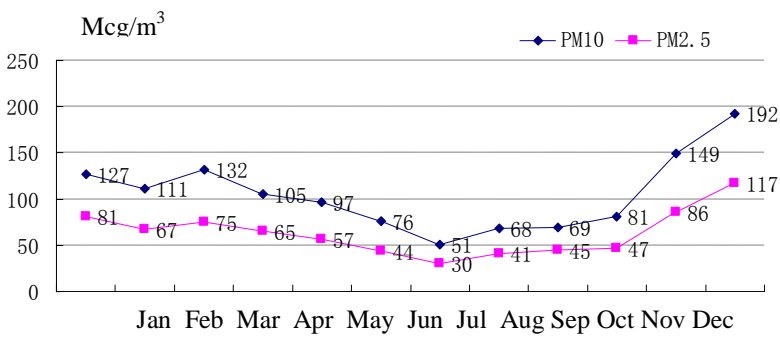

Fig. 6. $\mathrm{PM}_{10}$ and $\mathrm{PM}_{2.5}$ concentration changes during Jan-Dec 2016, Chengdu.

Except in Jul, Aug and Sep, $\mathrm{PM}_{10}$ concentrations in other months all exceed national ambient air quality Level II standard; $\mathrm{PM}_{2.5}$, excluding July, does the same. The line charts of two pollutants are in positive correlation, and the pollutant concentration distributes as a V shape, both reach the peak in Dec. Main source of pollutants is vehicle tai gas industrial construction at Circle I, and residuals from industrial production in Circle II, which spread to Circle I in air, most contain heavy metals or other toxic substances. For the scenic spots in Chengdu are located in downtown area, the air concentration there is the same as that in the city. "Fig. 5"

$\mathrm{PM}_{10}$ and $\mathrm{PM}_{2.5}$ can float in air for a long time, the higher their concentration in air, the more serious the air pollution is. $\mathrm{PM}_{10}$ is also called inhalable particles, whose aerodynamic equivalent diameter is not more than 10 micron. When its concentration increases by $10 \mathrm{mcg} / \mathrm{m} 3$, respiratory system disease mortality and cardiovascular disease mortality of the people will increase by $0.65 \%$ and $0.40 \%$ respectively; $\mathrm{PM}_{2.5}$ is also called respirable particle, whose aerodynamic equivalent diameter is not more than 2.5 micron. Compared to coarse atmospheric particulates, $\mathrm{PM}_{2.5}$ has small size, large area, high activity, vulnerable to toxic and harmful substances, long duration in air and long transport distance, so it has more serious influence to human health and air quality. When $\mathrm{PM}_{2.5}$ concentration increases by $10 \mathrm{mcg} / \mathrm{m} 3$, the acute morality of the people will increase by $0.40 \%$, respiratory system disease and cardiovascular disease mortality will increase by $1.43 \%$ and $0.53 \%$ respectively. "Fig. $6 "$

\section{GREEN SUSTAINABLE DESIGN CONCEPT}

Scenic spot is an ideal place for relaxation and amusement, however, current air in scenic spots has been polluted. Green eco-design and sustainable design are adopted for air control, which can not only promote the sustainable and health development of scenic spots but also make use of all kinds of resources for air control to the maximum.

Green eco-design concept: Key technique of green design is Design for Environment (DFE), a new design concept developed in the green tide around the world. DFE is a product design on the basis of technology for environment. Green product design is conducted on main pollutants in scenic spots, and an overall design is done with special environment as base and special cultural deposits in scenic spots.

Sustainable design concept: Air pollution control needs scientific guidance and design, with sustainable design adopted for scenic spots and intensive design of environmental factors, it can maximally save natural resources and energies in order to get the optimal integrated benefits through the most reasonable input, and the scenic spots will better satisfy the people in spirit and body.

\section{STRATEGIES FOR ECO-DESIGN}

\section{A. Set Critical Value for Environmental Capacity in Scenic Spots}

Adopt fusing mechanism for scenic spots, set critical value for environmental capacity, control numbers of tourists so to as guarantee normal environment in scenic spots. When the pollutant concentration is highly exceeding standards in scenic 
spots, the online platform and offline publicity in situ will start to evacuate tourists and reduce the pressure so as to keep the environmental capacity and tourists healthy in scenic spots.

\section{B. Build a Green Eco-chain in Scenic Spots}

1) Introducing green eco-plants to purify air: Increase quantity of trees in cities, introduce green eco-plants to purify air and build a plant-based compound structure land. For plants are seasonal, it is suggested to plant broadleaf arbor grass, broadleaf trees, tree and shrub grass, coniferous arbor grass, peony, lawn and more, make rational arrangement when planting, form a compound layer structure, which can not only purify and absorb both $\mathrm{PM}_{10}$ and $\mathrm{PM}_{2.5}$ particles but also increase humidity of scenic spots. In winter, $\mathrm{PM}_{10}$ and $\mathrm{PM}_{2.5}$ concentrations are generally higher, it is suggested to plant white pine and Chinese pine, whose particle adoption is (18.95 \pm 0.71$) \mu \mathrm{g} . \mathrm{cm}-2$ and $(14.61 \pm 0.78) \mu \mathrm{g} . \mathrm{cm}-2$ respectively.

2) Introduce new degradable soil organism: With regard to main pollutants attached on the ground such as $\mathrm{PM}_{10}$ and $\mathrm{PM}_{2.5}$ particles, new degradable soil organism can be used for absorption and degradation in order to prevent particles from floating or polluting the air once again. In addition, bioreactor technique can be adopted to absorb particles through biofunctions owned by microorganism.

3) Introduce ecological cycle water system: Landscape water. According to actual conditions in scenic spots, design fancy fountains matching with local landscape cultural concept, and spraying water is used to absorb particles in air in order to low particle concentration and improve the air quality.

Sponge ground tiles and water resource recovery. With the sponge city concept gradually accepted by the people, the creative concept is to use water permeable bricks to protect water resources underground, improve hot air environment in cities and reduce damages to eco-environment on the ground. The concept can be used for scenic spots, promote the use of water permeable bricks and protect eco-environment in scenic spots.

TABLE IV. WEATHER STATISTICS IN DECEMBERS, 2015, 2016 , CHENGDU

\begin{tabular}{llllll}
\hline Year & Overcast & Cloudy & Fine & \multicolumn{2}{c}{ Rainy } \\
\hline 2015 & 14 & 10 & 4 & 3 & \\
\hline 2016 & 11 & 10 & 9 & 1 & \\
\hline & & & & & ${ }^{c} \cdot$ Unit : Day
\end{tabular}

Artificial rainfall: "Table IV" shows, there were 3 rainy days in Dec, 2015, 1 day in Dec 2016, Chengdu, yet, $\mathrm{PM}_{10}$ and $\mathrm{PM}_{2.5}$ concentration both peaked in Dec. Artificial rain fall means, according to clouds' physical characteristics, a proper chance is caught to cause cloud water fall or increase precipitation. When natural clouds bring rainfall or are ready for rainfall, the artificial rainfall will succeed more easily. Generally there is higher humidity in scenic spots than those in downtown areas, besides, there are many overcast days in Chengdu, so in case of higher air particle concentration, artificial rainfall can be conducted to absorb dust and low the pollutant concentration.

\section{Create a Green Product Chain in Scenic Spots}

1) Negative ion air purifying lamp: Innovative design of solar energy-based smart tiny particle air purifying lamp in scenic spots. Working principle of the lamp: it energized through solar panel to make use of single-chip negative ion emitters, dust retention and removal pipes and super highspeed bladeless fan to absorb, settle and deposit tiny particle pollutants, which can save energy, clarify and improve the environment. "Fig. 7"

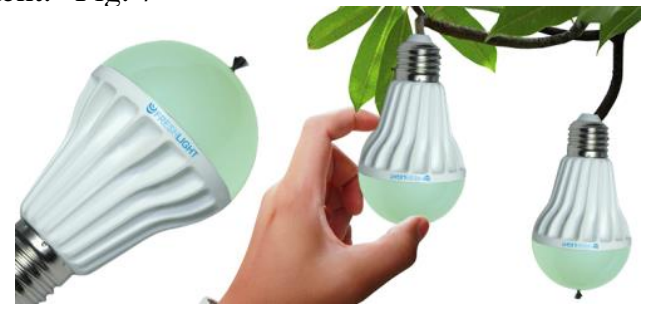

Fig. 7. Negative ion air purifying lamp.

2) Green imitated purifying plants: Conduct innovative design on product shapes according to green plant appearance and aesthetic perception as well as aesthetic demand of the people, and design green imitated purifying plants matching with scenic spots.

Based on tree shapes, design air imitated purifying trees. Working principle: take leaves and trunks as air inlet and outlet, install a purifying system at the bottom of imitated trees, and emit gas after filtration and deposit particle pollutants. The imitated air purifying trees can not only be integrated to the environment in scenic spots but also purify air; Based on lawn shapes, the artificial purifying lawns can not only be used for amusement but also as green lungs in scenic spots to adjust air humidity and keep the air fresh. "Fig. 8"

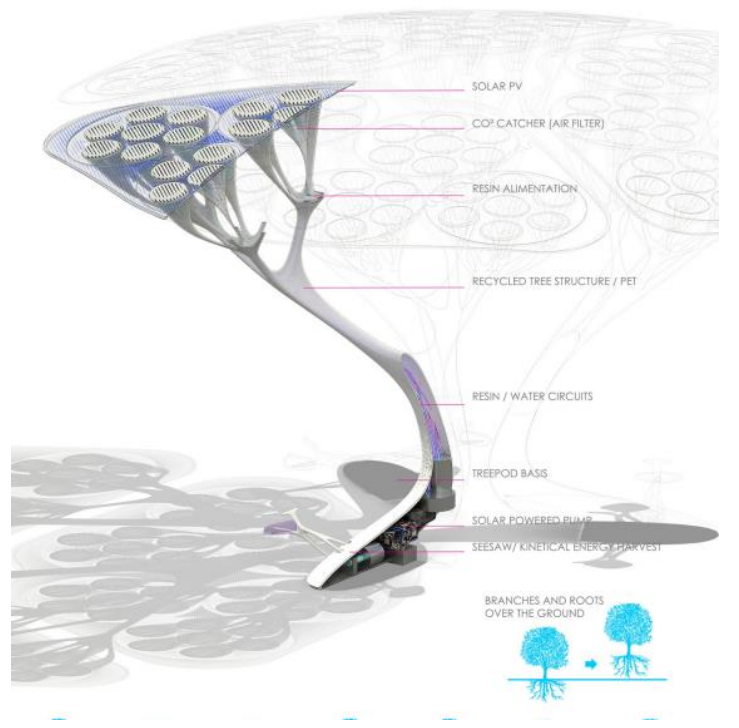

Fig. 8. Imitated trees. 
3) Integration of green cultural creative products with facilities in scenic spots: Conduct mini cultural creative product design as per features in scenic spots, take Chengdu Panda base as example, we can take small panda as prototype for creative design of indoor and outdoor air purifying products that can be placed rest areas in scenic areas for air purification and amusement. "Fig. 9"

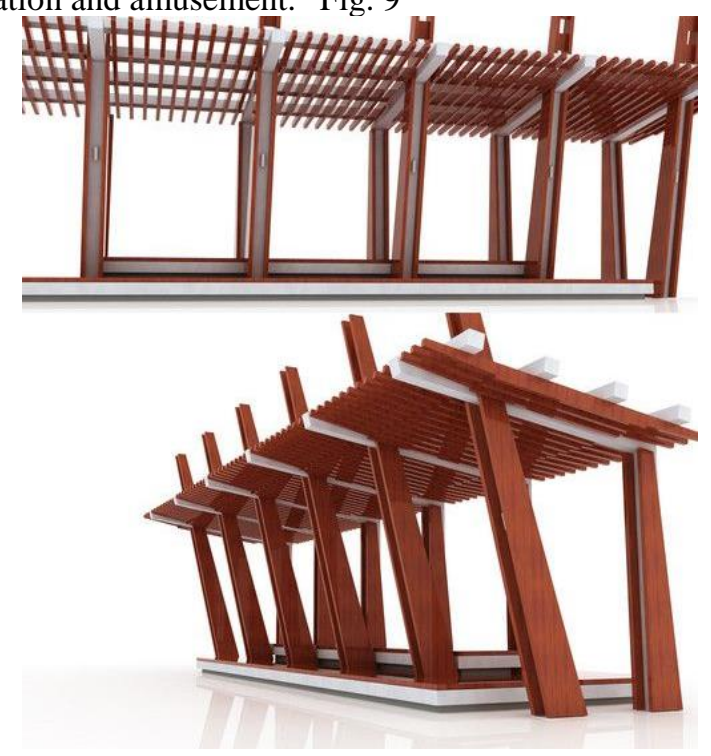

Fig. 9. Conceptual rest pavilion in scenic spots.

4) Design of green parking lot for self-driving travel: $\mathrm{NO}_{2}$ pollutants in scenic spots, Chengdu, mainly come from tail gas of motor vehicles. Green travel is raised through channels for vehicles before entering the scenic spots, and cities are advocated to take bus or tail gas free electric vehicles to travel. When motor vehicles reach scenic spots, green parking lot shall be ready with green plants around it. The site may adopt pervious or air permeable concrete, professional space design shall be made under the parking lot, making it able to absorb tail gas and be penetration beds for rainwater, parks and trees. Green parking lot can not only reduce the spread of tail gas as $\mathrm{NO}_{2}$ but also purify the air through shady trees and promote the efficient control on rainfall runoff.

\section{CONCLUSION}

The analysis results show main air pollutants are $\mathrm{NO}_{2}$, $\mathrm{PM}_{10}$ and $\mathrm{PM}_{2.5}$ in scenic spots, Chengdu, based on green design concept for air purification, this article raises the setting of critical value for environmental capacity in scenic spots and the creation of green eco-chains and product chains in order to purify and reduce main air pollutants.

\section{REFERENCES}

[1] Xie Peng, Liu Xiaoyun, Liu Zhaorong, et al, Exposure-response functions for health effects of ambient particulate matter pollution applicable for China [J]. China Environmental Science, 2009, 29(10) : 1034-1040.
[2] Yang Xue, Discussion on Sustainable Landscape Design Method [J]. Heilongjiang Science and Technology of Water Conservancy, 2015, 43(8). 79-81.

[3] Wu Zhiping, Wang Cheng, Hou Xiaojing, et al, Research on Air PM2.5 Concentration Change Rules by Six Urban Green lands [J]. Journal of Anhui Agricultural University, 2008, 35(4). 494-498.

[4] Wang Bing, Zhang Weikang, Niu Xiang, et al, Research on Absorption of 10 Evergreen Tree Varieties in Beijing [J]. Environmental Science, 2015, (2). 408-414.

[5] Li Qingcai, Zhai Longtao, Xu Longhe, et al, Design and Research on New Solar Energy Small PM2.5 Air Purifier [J]. Shanxi Electronic Technology, 2017,(01) 75-77. 